\title{
Aspirin attenuates the anti-inflammatory effects of theophylline via inhibition of cAMP production in mice with non-eosinophilic asthma
}

\author{
Hyung-Geun Moon, You-Sun Kim, \\ Jun-Pyo Choi, Dong-Sic Choi, \\ Chang Min Yoon, Seong Gyu Jeon, \\ Yong Song Gho ${ }^{1}$ and Yoon-Keun Kim ${ }^{1}$ \\ Department of Life Science \\ POSTECH Biotech Center \\ Pohang University of Science and Technology (POSTECH) \\ Pohang 790-784, Korea \\ ${ }^{1}$ Corresponding authors: Tel, 82-54-279-2345; \\ Fax, 82-54-279-8611; E-mail, ysgho @ postech.ac.kr (Y.S. Gho), \\ Tel, 82-54-279-2125; Fax, 82-54-279-8449; \\ E-mail, juinea@postech.ac.kr (Y.K. Kim) \\ DOI 10.3858/emm.2010.42.1.005
}

Accepted 25 September 2009

Available Online 4 November 2009

Abbreviations: AERD, ASA-exacerbated respiratory tract disease; ASA, acetylsalicylic acid; BAL, bronchoalveolar lavage; COPD, chronic obstructive pulmonary disease; $L N$, lymph node; $S A$, salicylic acid; Th1 cell, type $1 \mathrm{~T}$ helper cell; WT, wild type

\begin{abstract}
Theophylline is commonly used to treat severe asthma and chronic obstructive pulmonary disease (COPD) characterized by non-eosinophilic inflammation. Acetyl salicylic acid (ASA) is one of the most widely used medications worldwide, but up to $20 \%$ of patients with asthma experience aggravated respiratory symptoms after taking ASA. Here we evaluated the adverse effect of ASA on the therapeutic effect of theophylline in mice with non-eosinophilic asthma. A non-eosinophilic asthma mouse model was induced by airway sensitization with lipopolysaccharide-containing allergen and then challenged with allergen alone. Therapeutic intervention was performed during allergen challenge. Theophylline inhibited lung inflammation partly induced by Th1 immune response. ASA attenuated the beneficial effects of theophylline. However, co-administration of the ASA metabolite salicylic acid (SA) showed no attenuating effect on theophylline treatment. The therapeutic effect of theophylline was associated with increase in cAMP levels, which was
\end{abstract}

blocked by co-treatment of theophylline and ASA. ASA co-treatment also attenuated the anti-inflammatory effects of a specific phosphodiesterase 4 inhibitor. These results demonstrate that ASA reverses anti-inflammatory effects of theophylline, and that ASA exerts its adverse effects through the inhibition of CAMP production. Our data suggest that ASA reverses lung inflammation in patients taking theophylline, although clinical evidence will be needed.

Keywords: adverse effect; aspirin; asthma, aspirin-induced; cyclic AMP; cyclic nucleotide phosphodiesterases, type 4; drug toxicity; pneumonia; theophylline

\section{Introduction}

Asthma is a complex syndrome with many clinical phenotypes in both adults and children. Its major characteristics include a variable degree of airflow obstruction, airway hyperresponsiveness, and eosinophilic or non-eosinophilic inflammation (Busse and Lemanske, 2001). Current asthma treatment protocols for those with severe symptoms or in need of frequent relief (more than twice weekly) recommend the use of preventative medications such as inhaled corticosteroids, which suppress inflammation and reduce swelling of the airway lining (Bateman et al., 2008). If symptoms persist, additional anti-inflammatory drugs, such as theophylline, are added until the condition is controlled (Busse and Lemanske, 2007; Bateman et al., 2008). Persistent asthma may be associated with significant neutrophilic lung inflammation (Gibson et al., 2001), and in patients with difficult-to-control asthma, neutrophils rather than eosinophils often predominate (Green et al., 2002). Meanwhile, chronic obstructive pulmonary disease (COPD) is a severe clinical condition that is characterized by irreversible airflow limitations (Scanlon et al., 2000). The pathophysiology of irreversible airway obstruction in COPD is multifactorial and, similar to severe asthma, involves neutrophilic inflammation (Keatings et al., 1996). Theophylline is also one of commonly used drugs for the treatment of COPD (Celli and MacNee, 2004). 
A

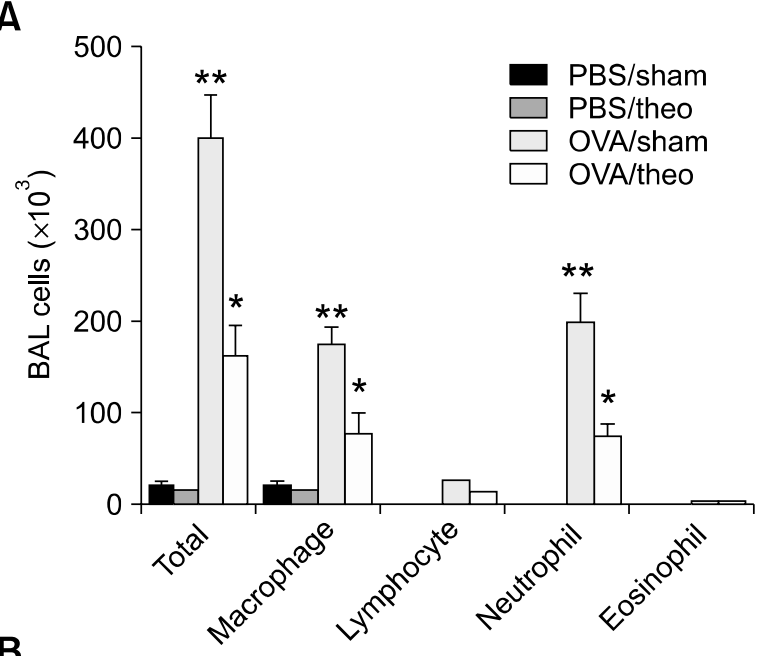

B

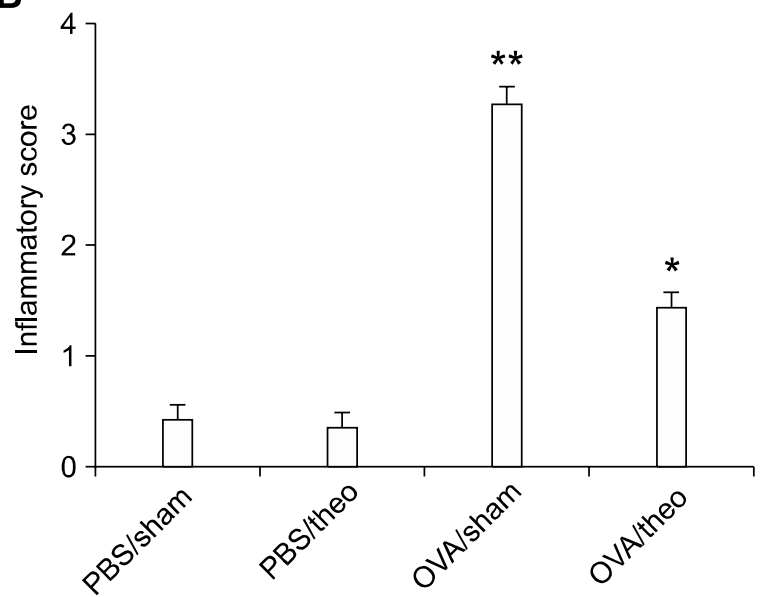

D

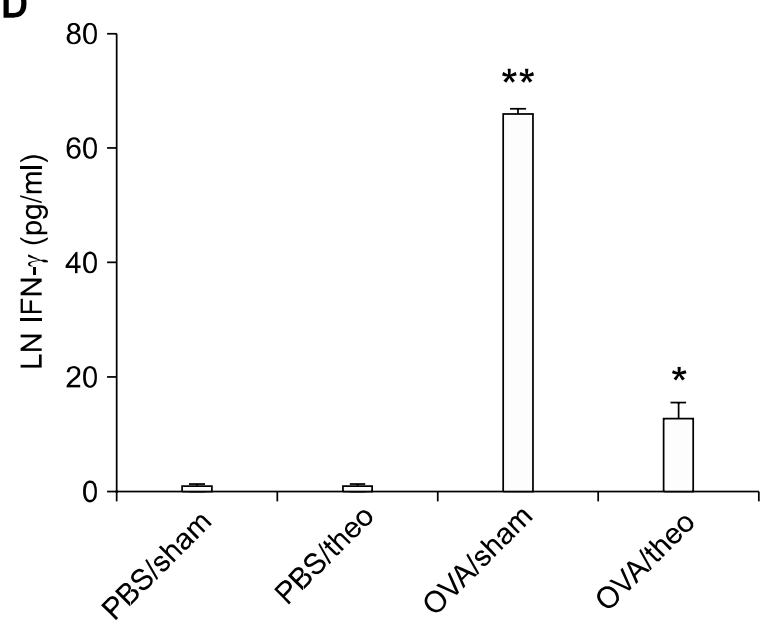

C

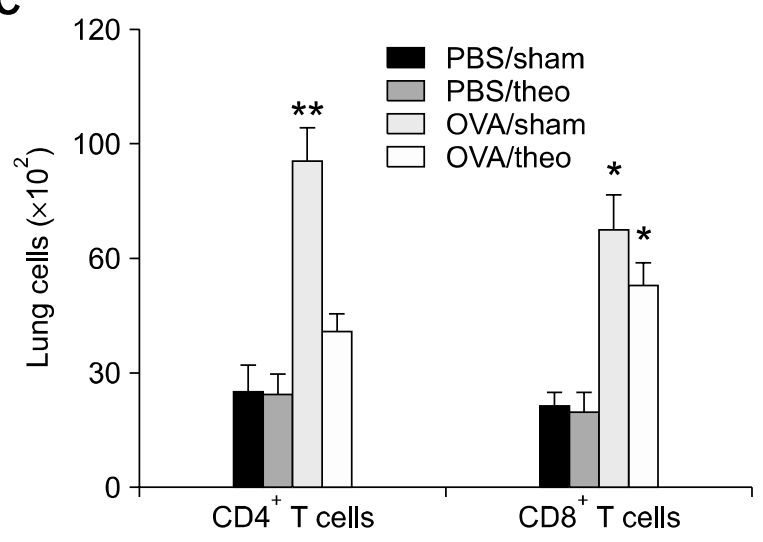

\section{a}
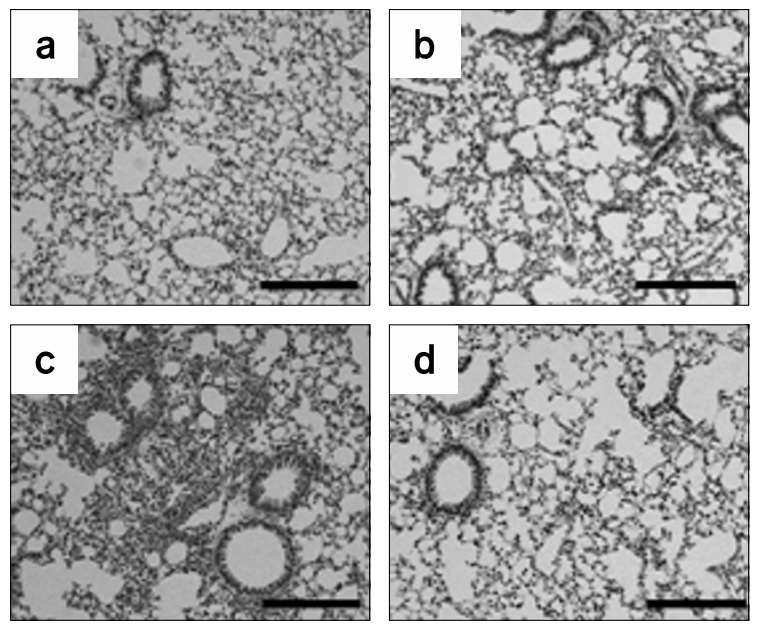

E

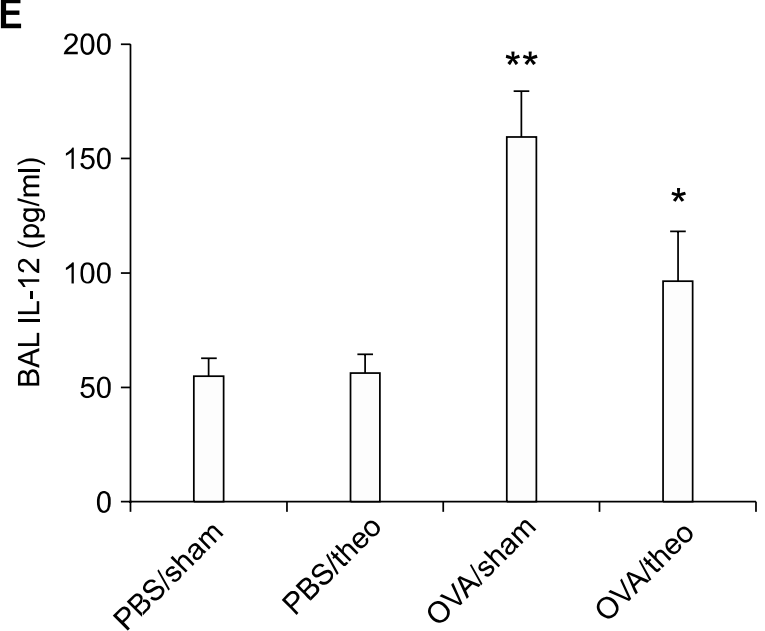

Figure 1. Theophylline shows therapeutic effects on neutrophilic inflammation induced by lipopolysaccharide-containing allergens. Evaluation ( $n=5$ each group) was performed after allergen challenge. PBS, mice sensitized with ovalbumin and then challenged with PBS; OVA, mice sensitized with ovalbumin + lipopolysaccharide and then challenged with ovalbumin; ${ }^{*} P<0.05$ compared to the PBS sensitized groups; ${ }^{* *} P<0.05$ compared to other groups. (A) $\mathrm{BAL}$ cellularity $48 \mathrm{~h}$ after the final allergen challenge. (B) Lung inflammatory scores based on histology (left panel) and representative lung histological findings $48 \mathrm{~h}$ after the final allergen challenge. a: PBS_sham; b: PBS_theo; c: OVA_sham; d: OVA_theo (H\&E stain, $\times 200)$. Magnification bar $=200 \mu \mathrm{m}$. (C) Number of $\mathrm{CD}^{+}$and $\mathrm{CD} 8^{+}$T-cells in lung tissues $6 \mathrm{~h}$ after allergen challenge on day 21. (D) IFN- $\gamma$ levels in supernatants prepared from T-cells collected $6 \mathrm{~h}$ after anti-CD3 and anti-CD28 stimulation. T-cells were isolated from lung draining lymph nodes (LNs) $6 \mathrm{~h}$ after allergen challenge on day 21. (E) BAL IL-12p40 levels $48 \mathrm{~h}$ after the final allergen challenge. 
Theophylline, also known as dimethylxanthine and marketed under a variety of brand names, has been conventionally used as a bronchodilator to relieve airway obstruction (Pauwels et al., 1985); recently, its anti-inflammatory properties have been demonstrated to be more effective for the long-term control of asthma (Ward et al., 1993). Although theophylline has been in clinical use for more than 60 years, its exact pharmacologic mechanism(s) of action remains uncertain, although proposed mechanisms include non-specific inhibition of adenosine receptor signalling (Cushley et al., 1984) and increase of cAMP production due to phosphodiesterase inhibition (Rabe et al., 1995).

Acetylsalicylic acid (ASA), also known as aspirin, is one of the most widely used medications in the world, with an estimated 40,000 metric tons consumed each year (Warner and Mitchell, 2002). ASA is often used as an analgesic to relieve pains, as an antipyretic to reduce fever, and as an anti-inflammatory medication; this drug also has an anti-platelet or anti-clotting effect and is commonly used to prevent heart attacks, strokes, and blood clot formation (Lewis et al., 1983). However, ASA use may also lead to ASA-exacerbated respiratory tract disease (AERD), which is a common and often under-diagnosed disease that affects up to $20 \%$ of the adult asthmatic population (Hamad et al., 2004). This condition is associated with more severe asthma requiring theophylline treatment in addition to inhaled corticosteroids (Hamad et al., 2004; Morwood et al., 2005). A number of hypotheses regarding the pathogenesis of AERD have been proposed (Hamad et al., 2004). However, to the best of our knowledge, there are no data regarding pharmacodynamic interaction between ASA and theophylline, in the treatment of non-eosinophilic lung inflammation characterized by severe asthma and COPD. In the present study, we hypothesized that ASA would antagonize lung inflammation during treatment with theophylline.

\section{Results}

\section{Therapeutic effect of theophylline against non-eosinophilic lung inflammation induced by lipopolysaccharide-containing allergens}

Recently, we reported non-eosinophilic asthma phenotypes induced by airway sensitization with lipopolysaccharide-containing allergens, which are induced by allergen-specific type $1 \mathrm{~T}$ helper cell (Th1) response (Kim et al., 2007). We first evaluated the therapeutic effects of theophylline treatment on the development of lung inflammation in the lipopolysaccharide asthma model. To test this, theophylline $(10 \mathrm{mg} / \mathrm{kg})$ was administered intraperitoneally during allergen challenge on days $14,15,21$, and 22 . Theophylline reduced the number of inflammatory cells (especially neutrophils) in BAL fluids, the production of which increased after sensitization with lipopolysaccharide-containing allergen (ovalbumin/lipopolysaccharide) (Figure 1A). Histological analysis of the lung showed that peribronchiolar and perivascular inflammatory cell infiltration (as indicated by inflammatory scores) also decreased significantly in ovalbumin/lipopolysaccharide-sensitized mice treated with theophylline, compared to sham-treated ovalbumin/ lipopolysaccharide-sensitized mice (Figure 1B). In addition, theophylline treatment reduced $\mathrm{CD}^{+}$ T-cell recruitment into the lung after allergen challenge (Figure 1C), and significantly inhibited IFN- $\gamma$ production by $\mathrm{T}$-cells in lung-draining $\mathrm{LNs}$ after stimulation with anti-CD3 and anti-CD28 (Figure 1D). Similarly, the levels of IL-12 (a downstream cytokine of IFN- $\gamma$ ) were decreased significantly in BAL fluids collected from theophylline-treated, ovalbumin/lipopolysaccharide-sensitized mice compared to sham-treated mice sensitized in the same manner (Figure 1E). Taken together, these findings suggest that theophylline treatment reduces lung inflammation primarily through inhibition of allergen-specific Th1 immune response.

\section{Adverse effects of ASA on the anti-inflammatory effects of theophylline}

Based on the results that theophylline inhibits lung inflammation, we then assessed the adverse effects of ASA when co-administered with theophylline. WT C57BL/6 mice were treated with theophylline and ASA in combination during allergen challenge in the lipopolysaccharide asthma model. This study showed that ASA treatment did not inhibit lung inflammation induced by ovalbumin/lipopolysaccharide sensitization (Figure 2A). However, co-treatment with theophylline and ASA attenuated theophylline-reduced BAL cellularity in a dose-dependent manner; in addition, the recruitment of inflammatory cells into the lung (assessed by lung inflammatory score), which was blocked by theophylline, was re-initiated by ASA in a dose-dependent manner (Figure 2B). To further analyze the adverse effect of ASA on the anti-inflammatory effect of theophylline, we administered ASA at $18 \mathrm{mg} / \mathrm{kg}$.

\section{The role of IFN- $\gamma$ on the adverse effect of ASA on the anti-inflammatory effects of theophylline}

Because sensitization with lipopolysaccharide-con- 
A

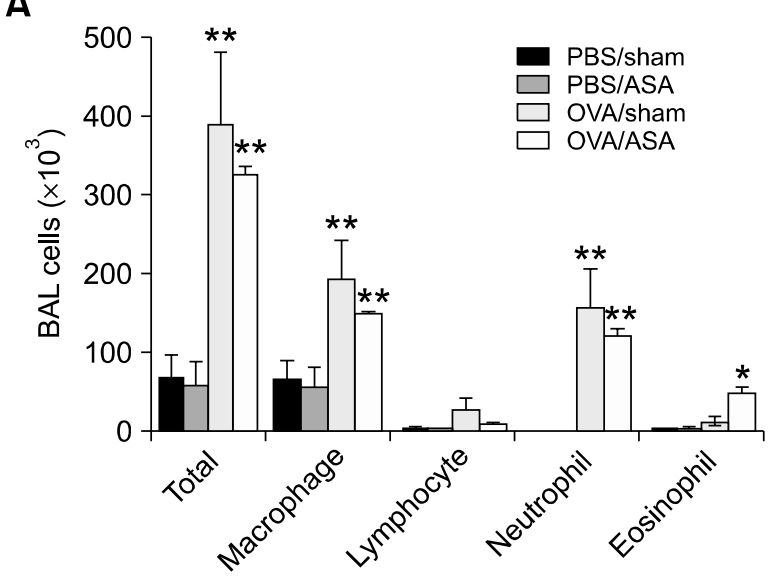

B

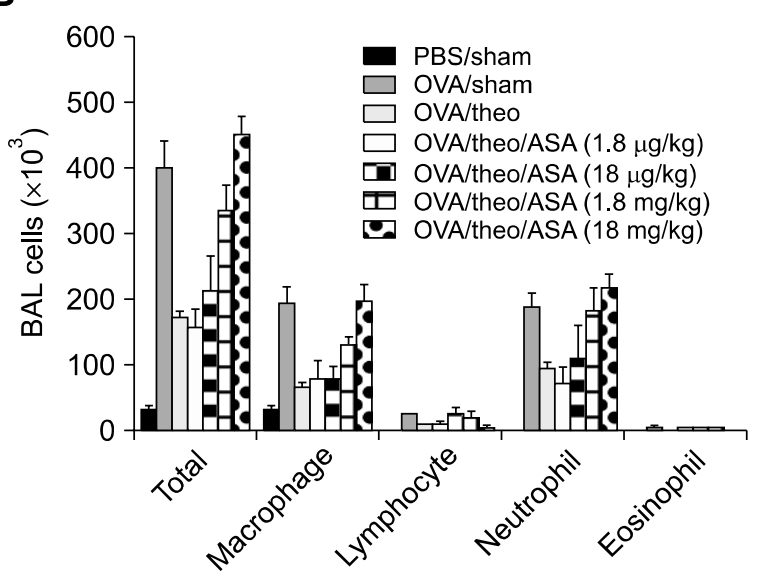

D

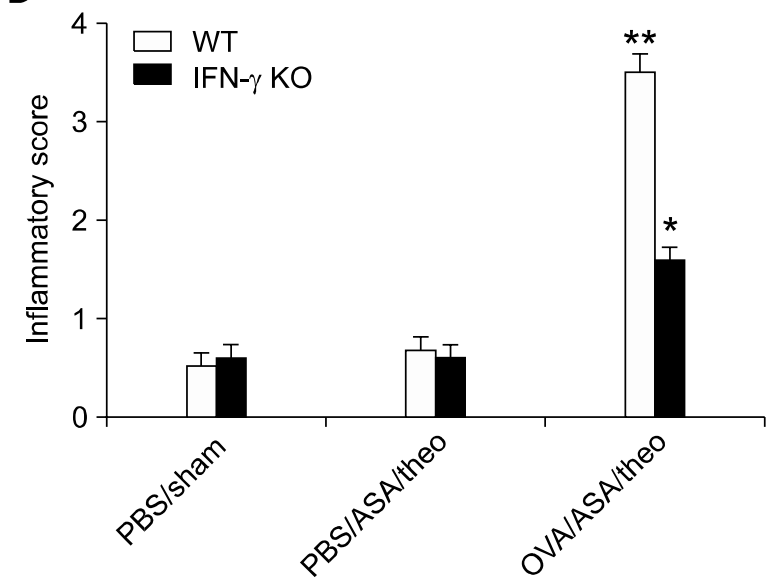

C
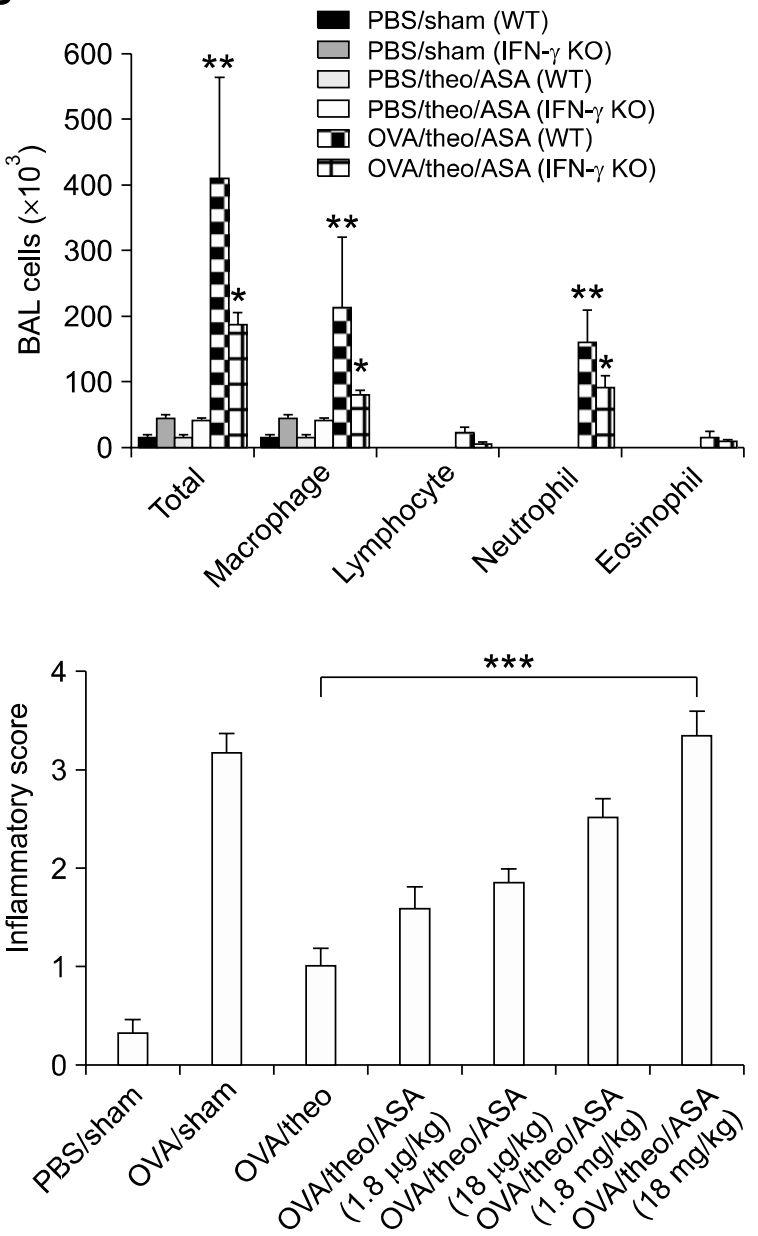

E

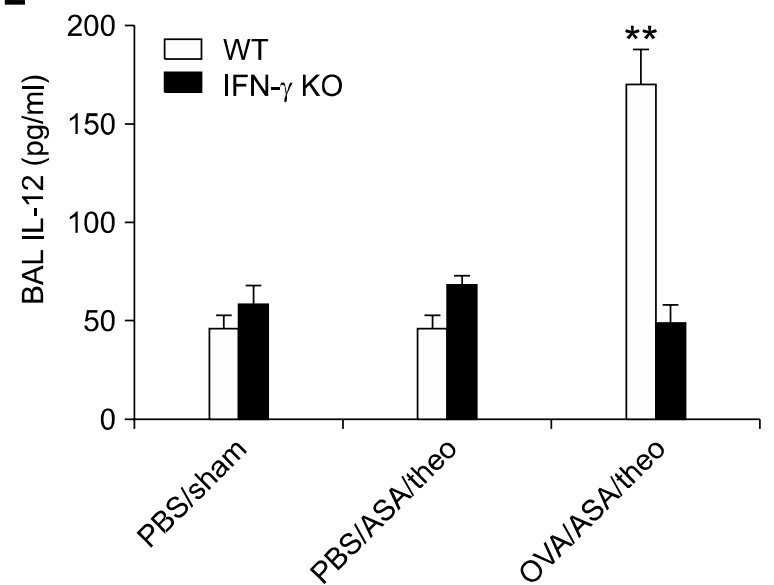

Figure 2. Acetylsalicylic acid (ASA) attenuates the therapeutic effects of theophylline. Evaluation ( $n=5$ each group) was performed $48 \mathrm{~h}$ after the final allergen challenge. PBS, mice challenged with PBS; OVA, mice sensitized with ovalbumin + lipopolysaccharide and then challenged with ovalbumin; ${ }^{*} P<$ 0.05 compared to the PBS groups; ${ }^{* \star} P<0.05$ compared to other groups; ${ }^{* * *} P<0.05$ by ANOVA linearity testing. (A) BAL cellularity in response to ASA $(18 \mathrm{mg} / \mathrm{kg}$ ) in wild type (WT) mice. (B) BAL cellularity (left panel) and lung inflammatory scores based on histology (right panel) in response to different doses of ASA. (C) BAL cellularity in IFN- $\gamma^{--}$and WT control mice in response to theophylline with or without ASA (18 mg/kg). (D) Lung inflammatory score based on histology in IFN- $\gamma^{-1-}$ and WT control mice. (E) BAL IL-12 levels in IFN- $\gamma^{-1-}$ and WT control mice. 
taminated allergens induces lung inflammation mainly via the Th1 immune response (Kim et al., 2007), we evaluated the role of IFN- $\gamma$ in ASA-exacerbated inflammation using IFN- $\gamma \mathrm{KO}$ and WT (both C57BL/6 background) mice. Theophylline + ASA co-treatment significantly reduced BAL cellularity in ovalbumin/lipopolysaccharide-sensitized IFN- $\gamma$ KO mice compared to WT mice sensitized in the same manner (Figure 2C). Similarly, inflammatory cell recruitment into the lung (assessed by inflammatory score) was significantly lower in the former group compared to the latter (Figure 2D). In addition, ovalbumin/lipopolysaccharide sensitization-induced IL-12 production was not detected in IFN- $\gamma \mathrm{KO}$ mice (Figure 2E). These findings suggest that ASA reverses the anti-inflammatory effects of theophylline primarily via the Th1 immune response.

\section{Adverse effects of ASA on the anti-inflammatory effects of systemic corticosteroid treatment}

Corticosteroids are potent anti-inflammatory drugs against lung inflammation in asthma and COPD patients. We evaluated the effects of systemic
A

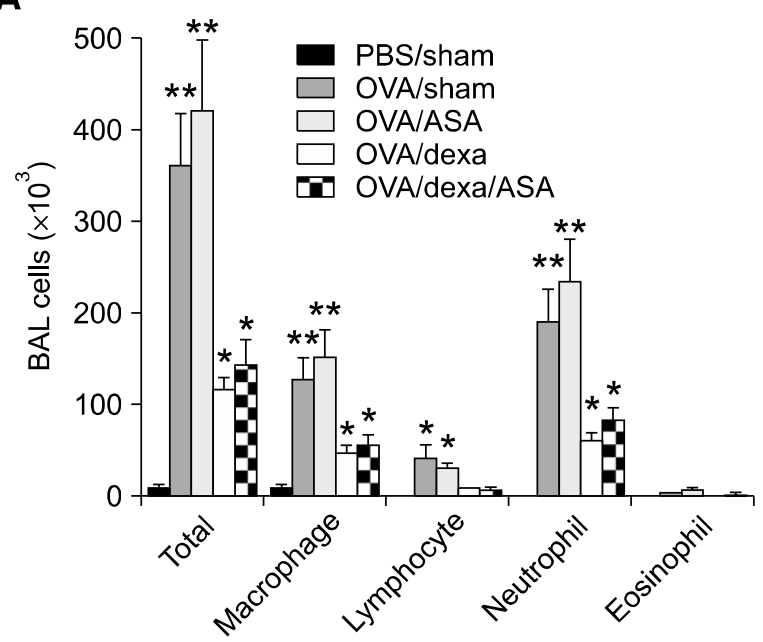

C
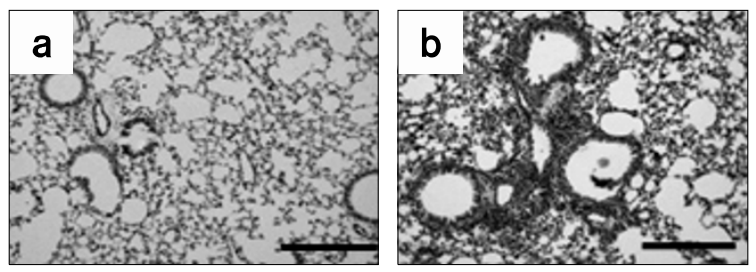

\section{c}
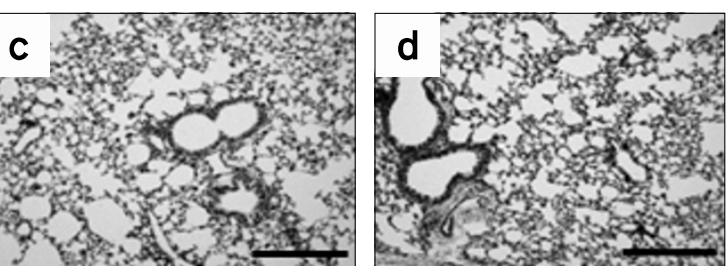

B

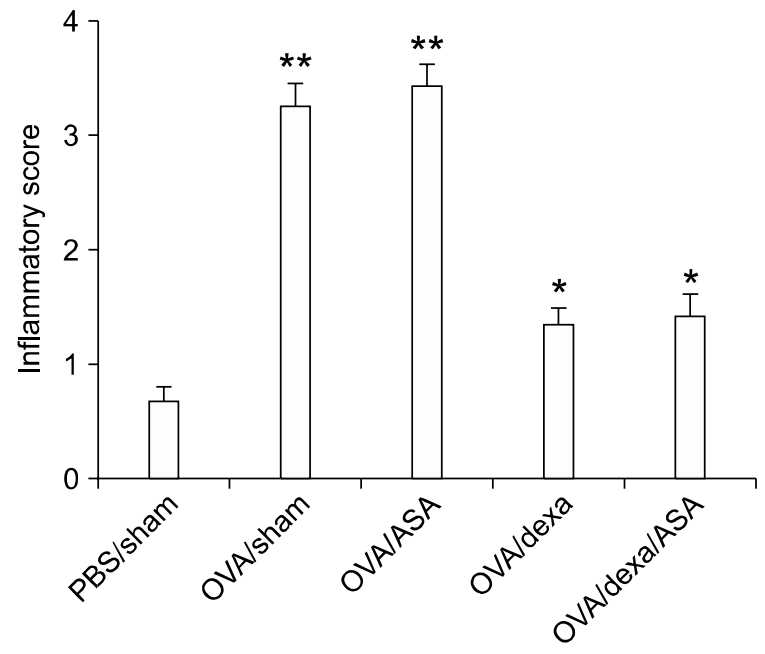

D

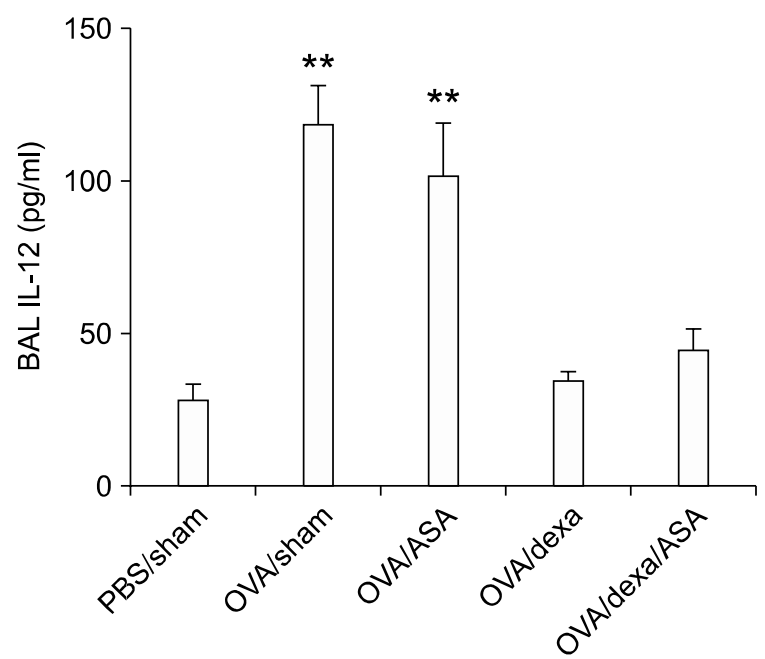

Figure 3. ASA shows no adverse effect on the anti-inflammatory properties of corticosteroid (dexamethasone). For all figures, evaluation ( $n=5$ each group) was performed $48 \mathrm{~h}$ after the last allergen challenge; PBS, mice challenged with PBS; OVA, mice sensitized with ovalbumin + lipopolysaccharide and then challenged with OVA; ${ }^{*} P<0.05$ compared to the PBS_sham group; ${ }^{*} P<0.05$ compared to the other groups. (A) BAL cellularity. (B) Lung inflammatory scores based on histology. (C) Representative lung histological findings. a: PBS_sham; b: OVA_ASA; c: OVA_dexa; d: OVA_dexalASA (H\&E stain, $\times 200$ ). Magnification bar $=200 \mu \mathrm{m}$. (D) IL-12 levels in BAL fluids. 
corticosteroid treatment, alone or in combination with $\mathrm{ASA}$, on the treatment of neutrophilic lung inflammation. WT C57BL/6 mice were treated intraperitoneally with a corticosteroid (dexamethasone, $10 \mathrm{mg} / \mathrm{kg}$ ) with or without ASA (18 mg/kg) during allergen challenge in the lipopolysaccharide asthma model. BAL cellularity, which increased in response to ovalbumin/lipopolysaccharide sensitization, was significantly inhibited by dexamethasone treatment alone, and ASA co-treatment did not attenuate this decrease in BAL cellularity (Figure 3A). Similarly, the ovalbumin/lipopolysaccharide sensitization-in- duced recruitment of inflammatory cells (lung inflammatory score) was decreased significantly after dexamethasone treatment alone; this effect was not attenuated by ASA co-treatment (Figure 3B); moreover, this beneficial effect was evident from lung histological findings (Figure 3D). Moreover, ovalbumin/lipopolysaccharide sensitization-induced IL-12 production was decreased significantly after both treatment of dexamethasone alone and co-treatment with dexamethasone and ASA (Figure 3D). These findings indicate that systemic corticosteroid treatment inhibits lung inflammation,
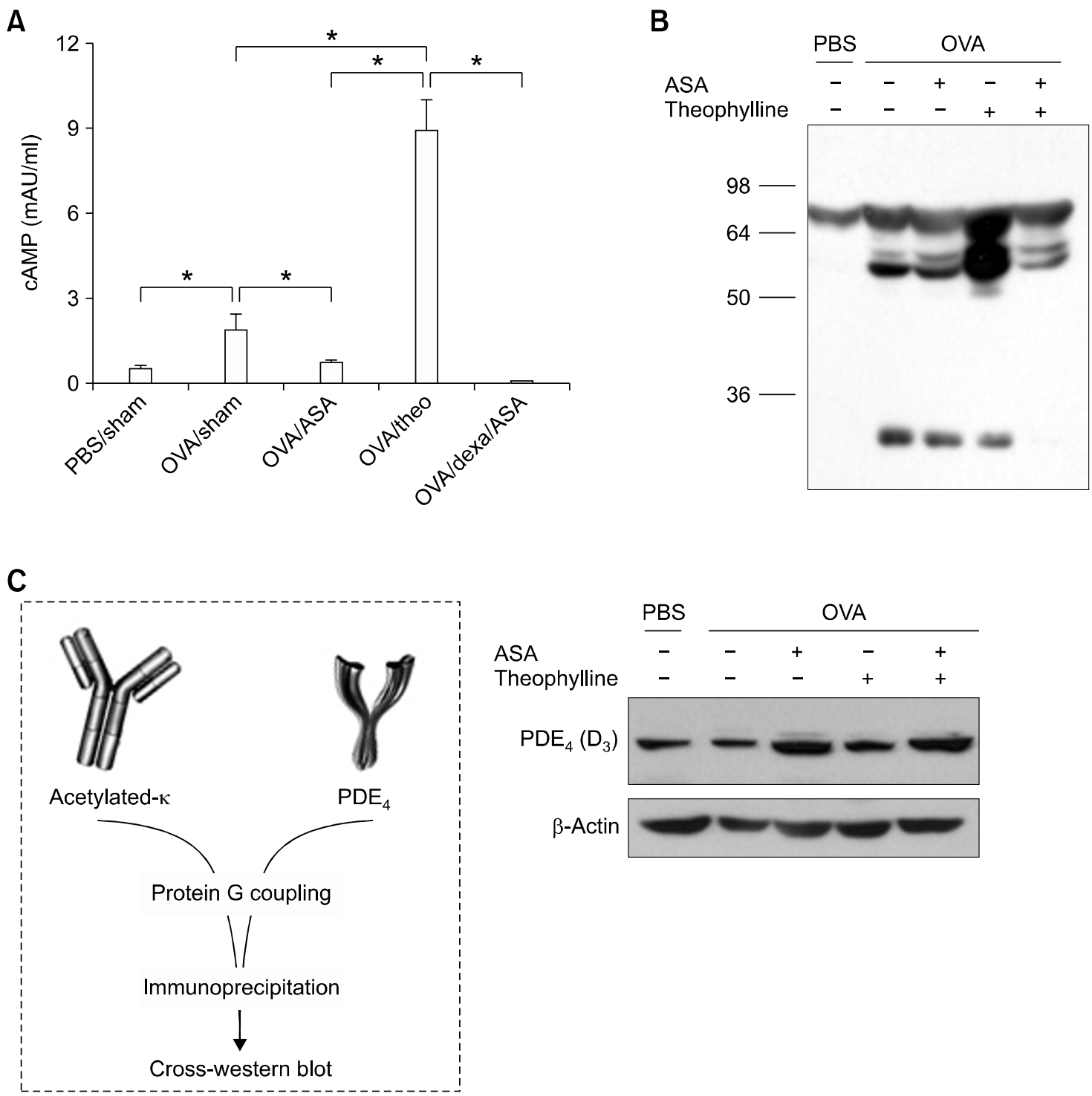

Figure 4. cAMP levels is negatively correlated with acetylated phosphodiesterase (PDE)4 in lung tissues. Evaluation was performed $6 \mathrm{~h}$ after the final allergen challenge; PBS, mice challenged with PBS; OVA, mice sensitized with ovalbumin + lipopolysaccharide and then challenged with ovalbumin. (A) Cyclic AMP levels in lung tissues. ${ }^{*} P<0.05$. Data from four mice in each group are shown. (B) Acetylation status of proteins isolated from lung tissues. (C) The protocol (left panel) and the levels of acetylated phosphodiesterase 4 (D3) in lung tissues (right panel) assessed by immunoprecipitation and cross-western blotting. 

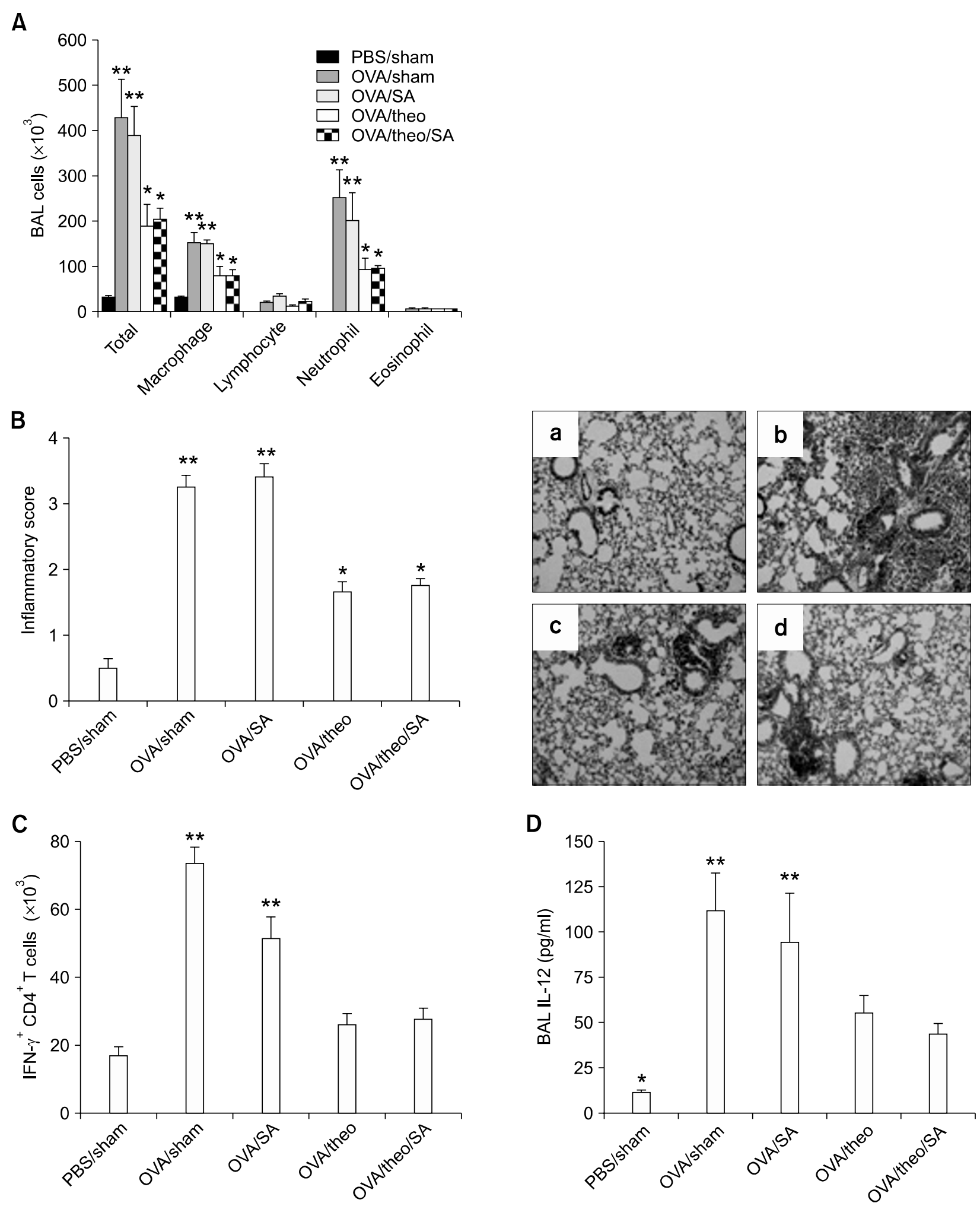

Figure 5. Salicylic acid (SA) does not attenuate the anti-inflammatory properties of theophylline. Evaluation ( $n=5$ each group) was performed after allergen challenge. PBS, mice challenged with PBS; OVA, mice sensitized with ovalbumin + lipopolysaccharide and then challenged with ovalbumin; ${ }^{*} P<$ 0.05 compared to the PBS_sham group; ${ }^{* *} P<0.05$ compared to the other groups. (A) BAL cellularity $48 \mathrm{~h}$ after the final allergen challenge. (B) Lung inflammatory scores based on histology $48 \mathrm{~h}$ after the final allergen challenge (left panel) and representative lung histological findings (right panel) obtained $48 \mathrm{~h}$ after the final allergen challenge (a: PBS; b: OVA_SA; c: OVA_theo; d: OVA_theo/SA, H\&E stain, $200 \times$ ). (C) Number of IFN- $\mu$-producing CD4 T-cells in lung tissues $6 \mathrm{~h}$ after allergen challenge on day 21. (D) IL-12 in BAL fluids collected $48 \mathrm{~h}$ after the final allergen challenge. 
and that ASA does not attenuate this therapeutic effect.

\section{The effects of ASA on the production of CAMP}

One of the proposed action mechanisms for theophylline is the non-specific inhibition of phosphodiesterases, which results in increased intracellular cAMP levels (Rabe et al., 1995; Hidi et al., 2000). We found that lung cAMP levels was enhanced by ovalbumin/lipopolysaccharide sensitization compared to negative control mice; theophylline treatment significantly increased CAMP levels in the lungs of ovalbumin/lipopolysaccharide-sensitized mice compared to those treated with sham or ASA alone; however, the theophylline-enhanced CAMP levels were blocked by ASA co-treatment (Figure 4A). These findings suggest that theophylline treatment induces its beneficial effect via up-regulation of cAMP.

\section{The effects of ASA on the expression of phosphodiesterase 4}

The present study showed that acetylation status of proteins isolated from lung tissues after allergen
A

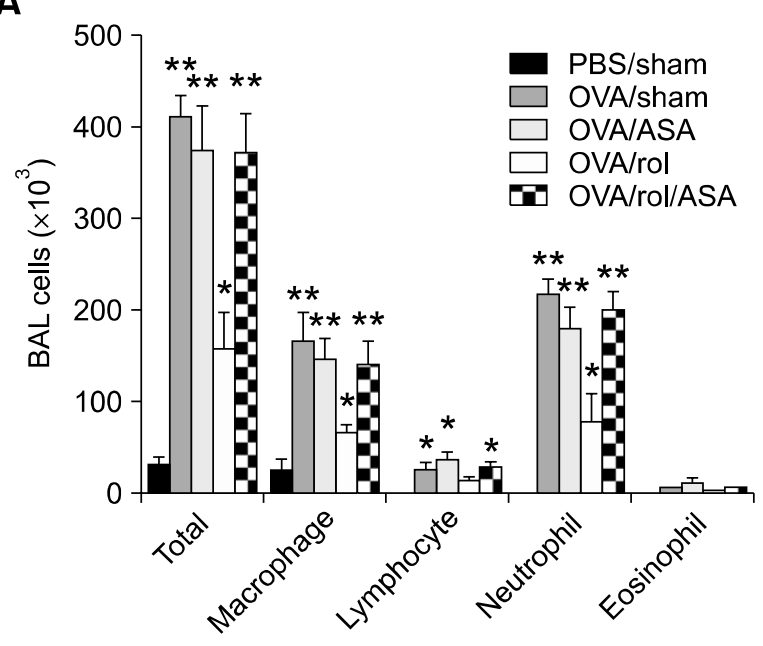

C
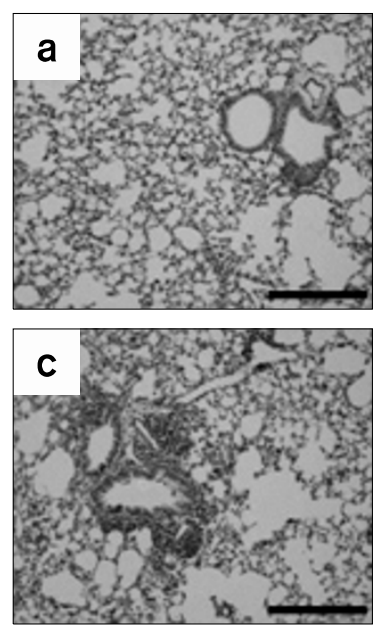
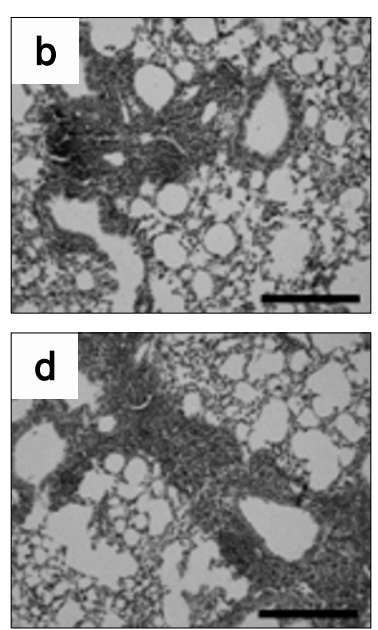

B

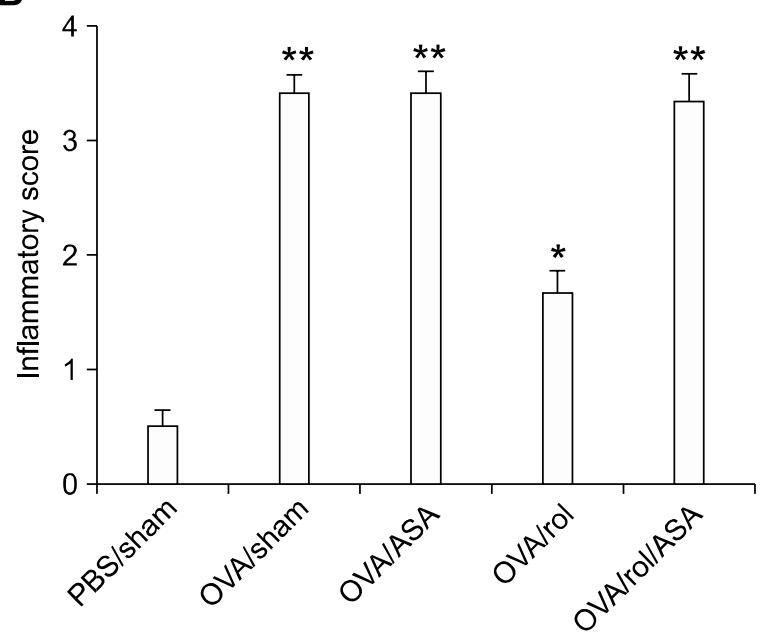

D

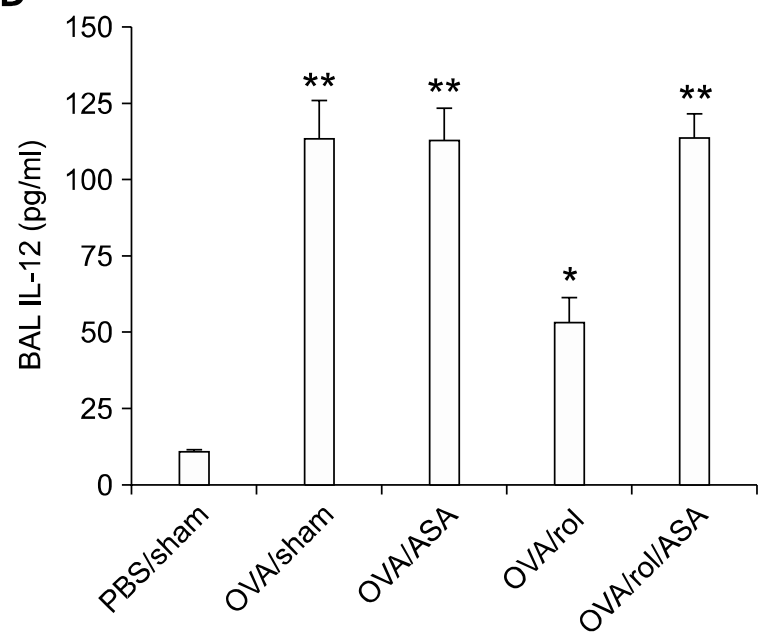

Figure 6. ASA attenuates the therapeutic properties of the phosphodiesterase 4 inhibitor rolipram. Evaluation ( $n=5$ each group) was performed $48 \mathrm{~h}$ after the final allergen challenge; PBS, mice challenged with PBS; OVA, mice sensitized with ovalbumin + lipopolysaccharide and then challenged with ovalbumin. ${ }^{*} P<0.05$ compared to the PBS_sham group; ${ }^{*} P<0.05$ compared to the other groups. (A) BAL cellularity. (B) Lung inflammatory scores based on histology. (C) Representative lung histological findings. a: PBS; b: OVA_ASA; c: OVA_rol; d: OVA_rol/ASA (H\&E stain, 200 $\times$ ). Magnification bar $=200 \mu \mathrm{m}$. (D) IL-12 levels in BAL fluids. 
challenge was different between PBS and ovalbumin/lipopolysaccharide sensitized mice; however, the acetylation status changed by ovalbumin/lipopolysaccharide sensitization was unaffected by treatment of ASA (Figure 4B). In contrast, acetylation status of lung proteins in mice sensitized with ovalbumin/lipopolysaccharide and treated with theophylline was altered by co-treatment of ASA (Figure 4B). These findings suggest that the adverse effect of ASA on the anti-inflammatory effect of theophylline may be related with acetylation of lung proteins altered by ASA. Among phosphodiesterases, the phosphodiesterase 4 subtypes form the predominant family in lung inflammatory cells (Dent et al., 1991; Hidi et al., 2000). This evidence led us to evaluate pharmacodynamic interactions on the phosphodiesterase 4 enzyme between ASA and theophylline in the lipopolysaccharide asthma model. As shown in Figure 4C, the amount of acetylated phosphodiesterase 4 (D3) subtype in lung tissues $6 \mathrm{~h}$ after allergen challenge was enhanced in ovalbumin/ lipopolysaccharide-sensitized mice treated with ASA alone compared to ovalbumin/lipopolysaccharide-sensitized mice treated with sham. In contrast, phosphodiesterase 4 was decreased in ovalbu$\mathrm{min} / \mathrm{lipopolysaccharide-sensitized} \mathrm{mice} \mathrm{treated} \mathrm{with}$ theophylline alone compared to ovalbumin/lipopolysaccharide-sensitized mice treated with ASA alone. However, the amount of phosphodiesterase 4 was increased in ovalbumin/lipopolysaccharide-sensitized mice treated with ASA + theophylline compared to ovalbumin/lipopolysaccharide-sensitized mice treated with theophylline alone. Taken together, these findings indicate that ASA enhances acetylated phosphodiesterase 4 in lung tissues, which may inhibit cAMP production.

\section{Adverse effects of SA on the anti-inflammatory effects of theophylline}

SA is produced when ASA is hydrolyzed by esterases in the liver and used as an anti-pyretic and anti-inflammatory drug (Rainsford and Whitehouse, 1980). To evaluate the potential adverse effects of SA moiety of ASA on theophylline therapy, WT C57BL/6 mice were treated with theophylline $(10 \mathrm{mg} / \mathrm{kg})$ with or without SA (10 $\mathrm{mg} / \mathrm{kg}$ ) during allergen challenge in the lipopolysaccharide asthma model. BAL cellularity was not decreased in response to SA treatment alone or SA + theophylline co-treatment in ovalbumin/ lipopolysaccharide-sensitized mice (Figure 5A). Similarly, ovalbumin/lipopolysaccharide sensitization-induced lung inflammation indicated by inflammatory scores was not decreased after SA treatment alone or SA + theophylline co-treatment; lung histology also showed that the beneficial effect of theophylline was not attenuated by SA co-treatment (Figure 5B). Moreover, the recruitment of IFN- $\gamma$-producing $\mathrm{CD}^{+}$T-cells into the lung was similar in ovalbumin/lipopolysaccharide-sensitized mice treated with theophylline alone and those co-treated with theophylline + SA (Figure 5C). In addition, theophylline-induced IL-12 down-regulation in ovalbumin/lipopolysaccharide-sensitized mice was unaffected by SA co-treatment (Figure 5D). These findings indicate that the adverse effect of ASA on theophylline-induced benefits is not related with the SA moiety of ASA.

\section{Adverse effects of ASA on the anti-inflammatory effects of a specific phosphodiesterase 4 inhibitor}

Among phosphodiesterases, phosphodiesterase 4 is the major cAMP-metabolizing enzyme, and phosphodiesterase 4 inhibitors are potential anti-inflammatory drugs, especially in inflammatory respiratory diseases such as asthma and COPD (Torphy et al., 1999). This evidence led us to evaluate the adverse effect of ASA on the therapeutic effect of a specific phosphodiesterase 4 inhibitor. WT C57BL/6 mice were treated with the specific phosphodiesterase 4 inhibitor rolipram (20 $\mathrm{mg} / \mathrm{kg}$ ) with or without ASA (18 $\mathrm{mg} / \mathrm{kg})$ during allergen challenge in the lipopolysaccharide asthma model. The present study showed that BAL cellularity was significantly lower in ovalbumin/lipopolysaccharide-sensitized mice treated with rolipram than in ovalbumin/lipopolysaccharide-sensitized mice treated with sham; however, this beneficial effect of rolipram was attenuated by ASA co-treatment (Figure 6A). Similarly, ovalbumin/lipopolysaccharide sensitization-induced lung inflammation, as indicated by increased inflammatory scores, was decreased significantly in response to treatment with rolipram alone, but this effect was also attenuated by the addition of ASA (Figures 6B and $6 \mathrm{C}$ ). Likewise, ovalbumin/lipopolysaccharide sensitization-induced IL-12 up-regulation was inhibited by treatment with rolipram alone; moreover, the rolipram-induced IL-12 down-regulation was reversed by ASA co-treatment (Figure 6D). These findings indicate that ASA reverses the anti-inflammatory effect due to phosphodiesterase 4 inhibition.

\section{Discussion}

ASA treatment is a cornerstone therapy for anti-pyretic treatment (400-500 mg/day) and pre- 
vention of atherosclerosis (75-325 mg/day), with an event-reduction rate of up to $33 \%$ (2002). However, some patients are unable to tolerate ASA, leading to AERD (Stevenson, 2004), this condition is more common in severe asthma (Hamad et al., 2004; Morwood et al., 2005), requiring theophylline treatment in addition to the regular use of inhaled corticosteroids (Bateman et al., 2008). Given the prevalence of atherosclerosis and chronic inflammatory lung diseases such as asthma and COPD, it is important to evaluate the adverse effects of ASA on non-eosinophilic lung inflammation (the underlying pathology of severe asthma and COPD) in patients undergoing theophylline therapy. To the best of our knowledge, we are the first to demonstrate that ASA reverses anti-inflammatory effects of theophylline and rolipram when ASA was simultaneously administered. Moreover, we found that the attenuating effect of ASA on theophylline-inhibited inflammation was related with decrease of CAMP production. These findings suggest that ASA reverses anti-inflammatory effects of theophlline by inhibition of cAMP production.

Although theophylline has been in use for several decades, its pharmacologic mode of action in asthma and COPD remains unclear. Theophylline has a bronchodilatory effect and effectively attenuates lung inflammation in asthma or COPD patients (Sullivan et al., 1994). In patients with nocturnal asthma, theophylline inhibits the influx of neutrophils and, to a lesser extent, eosinophils (Kraft et al., 1996). It also inhibits neutrophilic inflammation in patients with severe asthma (Wenzel et al., 1997; Jatakanon, et al., 1999; Kim et al., 2007), and COPD (Culpitt et al., 2002). In vitro, theophylline has inhibitory effects on inflammatory mediators released from neutrophils and on neutrophil chemotaxis (Nielson et al., 1988; Yasui et al., 2000). Similarly, our in vivo data indicate that theophylline inhibits neutrophilic lung inflammation induced by lipopolysaccharide-containing allergens. Taken together, these findings suggest that theophylline effectively inhibits non-eosinophilic lung inflammation in patients with asthma or COPD.

Theophylline exhibits several immunomodulatory properties. It reduces the recruitment of activated T-cells into the lungs of asthmatic individuals and decreases the number of activated T-cells in BAL fluids collected after allergen challenge (Kidney et al., 1995; Jaffar et al., 1996). Our previous data indicate that neutrophilic lung inflammation due to lipopolysaccharide-containing allergen sensitization occurs primarily through the Th1 immune response (Kim et al., 2007). Our present in vivo data show that theophylline inhibits the recruitment of Th1 cells into the lung after allergen challenge, thus reducing neutrophilic inflammation. Taken together, these findings suggest that theophylline reduces neutrophilic inflammation primarily through inhibition of the Th1 immune response.

Several action mechanisms of theophylline have been proposed. For example, at therapeutic concentrations, theophylline treatment is associated with the non-specific inhibition of adenosine receptors (Pauwels and Joos, 1995), which in turn result in its therapeutic effects including immune modulation (Zidek, 1999). However, some evidence indicates that extracellular adenosine attenuates $\mathrm{IL}-12$ production in dendritic cells and inhibits the initiation of the Th1 immune response (la Sala et al., 2001). Previous studies also showed that the in vivo activation of adenosine receptors in Th1 cells directly inhibited the expansion of Th1 cells (Erdmann et al., 2005). Our present data demonstrate that theophylline-induced inhibition of the Th1 immune response is positively associated with cAMP enhancement. Along with the evidence that adenosine is a metabolite of cAMP (Jackson et al., 1997), these findings suggest that the CAMP-adenosine pathway is a negative regulator of the Th1 immune response, and that the immune modulatory effect of theophylline is mediated by mechanism(s) other than its adenosine receptor antagonism.

Phosphodiesterases hydrolyze the phosphodiester bond present in cyclic second messengers, such as CAMP and CGMP; thus, treatment with the non-specific phosphodiesterase inhibitor theophylline results in increased CAMP and cGMP levels (Lugnier et al., 1986). Indeed, our present data showed that theophylline treatment enhanced CAMP production in lung tissues. The phosphodiesterase 4 subtypes form the predominant family of phosphodiesterases in inflammatory cells, including T-lymphocytes, neutrophils, eosinophils, mast cells, and macrophages (Dent et al., 1991; Hidi et al., 2000). In vitro data have indicated that phosphodiesterase 4 inhibitors reduce release of mediators from human neutrophils ( $\mathrm{Au}$ et al., 1998). Our in vivo data also showed that rolipram, a phosphodiesterase 4 inhibitor, reduced neutrophilic inflammation after an allergen challenge. These findings suggest that phosphodiesterase 4 inhibitors may be useful in the treatment of severe asthma and COPD, which may involve neutrophilic inflammation. Moreover, phosphodiesterase 4 inhibitors preferentially block the production of Th1 cytokines in vitro (Claveau et al., 2004). Here, we showed that rolipram blocked the Th1 immune response. Taken together, these findings suggest 
that the immunomodulatory and anti-inflammatory effects of theophylline in the asthma model are related with phosphodiesterase 4 inhibition.

SA is a hydrolytic metabolite of ASA that lacks the acetyl moiety present on ASA. Although metabolic drug interactions involving ASA are theoretically possible, no conclusive data exist to demonstrate that ASA affects the metabolism of co-administered drugs. ASA blocks the biosynthesis of prostaglandins from arachidonic acid (Roth et al., 1975), which is mediated by the incorporation of the acetyl moiety of ASA into cyclooxygenase (Roth et al., 1975). ASA selectively acetylates the Ser residue of cyclooxygenase-1, thereby inactivating cyclooxygenase activity of the enzyme without affecting peroxidase activity (Shimokawa and Smith, 1992). Furthermore, PGE2 is one of cyclooxygenase metabolite that controls inflammation in the lung (Vancheri et al., 2004). We have no experimental evidence whether this PGE2 may participate in reverse effects of ASA or not and SA has poor ability to block cyclooxygenase activity. However, like cyclooxygenase inhibition, ASA may inhibit phosphodiesterase 4 enzymatic activity through acetylates phosphodiesterase 4 certain residues because SA did not represent reverse effects of theophylline. Our present data indicate that the anti-inflammatory effects of theophylline are not inhibited by SA, suggesting that the acetyl moiety of ASA is responsible for the adverse effects of ASA on theophylline treatment. In the present study, we found that expression of phosphodiesterase 4 in lung tissues in the non-eosinophilic asthma model was enhanced by treatment of ASA. Moreover, we demonstrated that ASA attenuated the anti-inflammatory effect induced by phosphodiesterase 4 inhibition. Taken together, these findings suggest that the anti-inflammatory effects of theophylline via phosphodiesterase 4 inhibition appear to be attenuated via ASA that has possibility of phosphodiesterase 4 acetylation.

In summary, our data demonstrate that ASA attenuates the anti-inflammatory effects of theophylline when concomitantly administered with theophylline. Our present study suggest that ASA prescription is avoided in patients with asthma and COPD patients taking theophylline alone and combinatorial therapy with corticosteroids, although clinical evidence will be needed.

\section{Methods}

\section{Mice}

Wild type (WT) and IFN- $\gamma$ knockout (KO) (both C57BL/6 background) mice were purchased from Jackson Laboratories (Bar Harbor, ME), and were bred in an animal facility at Pohang University of Science and Technology (POSTECH) in Pohang, Republic of Korea. Animal study protocols were approved by the Institutional Animal Care and Use Committee of POSTECH Biotech Center (PBC).

\section{Chemicals and drugs}

To generate a non-eosinophilic asthma mouse model, lipopolysaccharide and ovalbumin was purchased from Calbiochem (Darmstadt, Germany) and Sigma-Aldrich (St. Louis, MO), respectively. Theophylline (aminophylline) was purchased from Daewon Pharmaceutical Co. Ltd. (Seoul, Korea), ASA (aspirin-lysine) from llyang Pharmaceutical Co. (Seoul, Korea), salicylic acid (SA) from Sigma-Aldrich (St, Louis, MO), and dexamethasone and rolipram from Calbiochem (La Jolla, CA). Lipopolysaccharide, ovalbumin, theophylline, ASA, and SA were dissolved in PBS and rolipram and dexamethasone in DMSO, respectively.

\section{Protocols for generation of a non-eosinophilic asthma mouse model and for pharmacologic intervention}

Lipopolysaccharide was depleted from ovalbumin as previously described (Kim et al., 2007). A mouse model with non-eosinophilic (or neutrophilic) inflammation was generated as previously described (Kim et al., 2007). Briefly, 6-week-old mice were sensitized intranasally with $75 \mu \mathrm{g}$ ovalbumin and $10 \mu \mathrm{g}$ lipopolysaccharide on days 0 , 1,2 , and 7 , and then challenged four times intranasally with $50 \mu \mathrm{g}$ ovalbumin on days $14,15,21$, and 22 . As a negative control, mice were sensitized with ovalbumin (75 $\mu \mathrm{g})$ alone and then challenged with PBS $(30 \mathrm{ml})$. Drugs (theophylline, ASA, dexamethasone, SA, and rolipram) were administrated intraperitoneally on days $14,15,21$, and 22. To evaluate the therapeutic and adverse effects of these drugs, ovalbumin-specific adaptive immune response and lung inflammation were evaluated $6 \mathrm{~h}$ after the ovalbumin challenge on day 21 and $48 \mathrm{~h}$ after the final ovalbumin challenge on day 22 , respectively.

\section{Cellularity in bronchoalveolar lavage (BAL) fluids}

BAL fluids were obtained as previously described (Kim et al., 2007). Briefly, mice were anesthetized with ketamin and trachea was isolated by blunt dissection. A small caliber tube was inserted and secured in the airway. Two successive volumes of $0.75 \mathrm{ml}$ of PBS were instilled and gently aspirated and these two volumes were pooled. Each BAL sample was centrifuged and the supernatants were stored at $-70^{\circ} \mathrm{C}$ until use. The total numbers of inflammatory cells were counted after dilution of cell pellets with $100 \mu$ of PBS. After Diff-Quick staining (Dade Behring) of BAL pellets in a cytospin preparation, types of inflammatory cells were determined by counting 300 cells, which were classified as macrophages, lymphocytes, neutrophils, or eosinophils. And then percentages of differential cell counts were re-calculated with total cell number. 


\section{Histological evaluation of lung inflammation}

Lung tissues were obtained as previously described (Kim et al., 2007). Briefly, the lung was perfused with cold PBS through the right ventricle until the pulmonary vasculature was clean. The whole lung was then inflated with histological fixative. Hematoxylin and eosin staining was performed after pressure fixation with Streck solution (Streck Laboratories, Omaha, NE). For the purposes of comparison, the same magnification was used for all sample slides. Furthermore, lung inflammation was scored according to the degree of peribronchiol and perivascular inflammation using a previously described subjective scale (Park et al., 2001). Briefly, values were assigned as follows: 0 , no infiltration was detectable; 1 , occasional cuffing with inflammatory cells; 2 , most bronchi or vessels surrounded by a thin layer (one to five cells) of inflammatory cells; and 3, most bronchi or vessels surrounded by a thick layer (more than five cells deep) of inflammatory cells. The inflammatory score was determined by summing the peribronchiolar and perivascular scores.

\section{Evaluation of immunological parameters}

To identify T-cells recruited into the lung, FACS analysis was performed using antibodies for T-cell surface markers, including anti-CD3, anti-CD4, and anti-CD8. After preparing single-cell suspensions from the lung tissue, cells were counted as previously described (Kim et al., 2007). To identify individual cells of interest, $1 \times 10^{6}$ isolated cells were aliquoted into tubes and stained with fluorescein isothiocyanate (FITC)-conjugated cell surface markers (BD Biosciences Pharmingen, San Diego, CA). To determine intracellular cytokine levels, isolated T-cells were incubated at $37^{\circ} \mathrm{C}$ for $3 \mathrm{~h}$ in RPMI medium containing $10 \%$ FBS and $2 \mu \mathrm{g} / \mathrm{ml}$ brefeldin A (Sigma-Aldrich), washed, and immunostained on ice for $30 \mathrm{~min}$. Cells were then washed in PBS containing $3 \% \mathrm{FBS}$ and $0.1 \% \mathrm{NaN}_{3}$, followed by fixation in PBS containing $4 \%$ formaldehyde for $20 \mathrm{~min}$. After washing, the cells were permeabilized with $0.5 \%$ saponin (Sigma-Aldrich) in PBS for $10 \mathrm{~min}$, centrifuged, re-suspended in $50 \mu \mathrm{l}$ of the same solution, and stained with anti-IFN- $\gamma$ antibodies for $30 \mathrm{~min}$. The cells were analyzed using a FACSCalibur system (BD Biosciences, Franklin Lakes, NJ), and the results were processed using CellQuest software (BD Biosciences). The number of cells in the lung was determined by multiplying total lung cells by the percentage of $\mathrm{CD}^{+}$or $\mathrm{CD}^{+}$T-cells. To measure cytokine expression in lung draining lymph nodes $(\mathrm{LNs})$, isolated T-cells $\left(1 \times 10^{6}\right.$ cells $)$ were stimulated with a nonspecific stimulus (anti-CD3 and anti-CD28) for $6 \mathrm{~h}$ and then the cytokines in the supernatants were measured via ELISA.

\section{ELISA}

IFN- $\gamma$ and IL-12 (p40 subunit) levels were quantified via ELISA as previously described (Kim et al., 2007).

\section{Evaluation of cAMP levels in lung tissues}

To determine cAMP levels in lung cells, samples were processed as previously described (Resta et al., 1997). In short, mice were sacrificed at $6 \mathrm{~h}$ after the ovalbumin challenge on day 21 and the lungs were frozen in liquid nitrogen. Later lung samples were homogenized in $0.85 \mathrm{ml}$ of ice-cold $0.4 \mathrm{~N} \mathrm{HClO}_{4}$. The samples were placed on ice for $15 \mathrm{~min}$ and then centrifuged for $2 \mathrm{~min}$ at $4^{\circ} \mathrm{C}$. The supernatants were transferred to a clean tube and $0.7 \mathrm{ml}$ of the supernatant were neutralized with $0.35 \mathrm{ml}$ of $0.6 \mathrm{M}$ $\mathrm{KHCO}_{3} / 0.72 \mathrm{M} \mathrm{KOH}$. The samples were clarified by centrifugation for 1-2 min at full speed in a microcentrifuge at $4^{\circ} \mathrm{C}$ and then analyzed by HPLC using a $0.50-\mathrm{ml}$ injection volume. The levels of cAMP were calculated from the areas under the respective peaks using authentic standards (cAMP purchased from Sigma-Aldrich) and an internal peak to correct for variations in extraction efficiency and sample loading.

\section{Western blot analysis and immunoprecipitation assay}

The protein concentrations of the whole cell lysate (WCL) using a DC protein assay kit (BioRad, Hercules, CA) with bovine serum albumin as the standard. The proteins in the WCLs $(30 \mu \mathrm{g})$ were separated by SDS-PAGE and transferred to PVDF membranes. After blocking with $3 \%$ non-fat skim milk in TBS with $0.05 \%$ tween-20 for $1 \mathrm{~h}$ at room temperature, the membranes were incubated for $2 \mathrm{~h}$ at room temperature with antibodies against phosphodiesterase 4 (Abcam, Cambridge, United Kingdom). Then the blots were washed and incubated with a secondary antibody conjugated to HRP (Santa Cruz Biotechnology, Santa Cruz, CA) for $1 \mathrm{~h}$ at room temperature. The immunoreactive bands were visualized using a chemiluminescent substrate.

For immunoprecipitation assay, phosphodiesterase 4 and acetylated lysine antibodies were coupled to Protein $G$ Magnetic Agarose Resin (Elpis biotech, South Korea). Antibodies coupling reaction was conducted in $1 \mathrm{mM}$ disuccinimidyl suberate solution (Pierce, Rockford, IL) and quenched by $50 \mathrm{mM}$ ethanolamine. Beads were washed with PBS and $1 \mathrm{M}$ glycine $(\mathrm{pH} 3)$ to remove unlinked antibodies. Beads were stored in PBS with $0.02 \%$ sodium azide until use. WCL $(100 \mu \mathrm{g})$ was incubated with antibodies coupled beads for overnight, washed with cell lysis buffer containing $50 \mathrm{mM}$ Tris-Cl (pH 7.5), 1\% NP-40, $0.25 \%$ Na-deoxycholate, $100 \mathrm{mM} \mathrm{NaCl}, 1 \mathrm{mM}$ EDTA and protease inhibitors and eluted in $2 \times$ SDS loading dye.

\section{Statistic analysis}

Significant differences among treatment groups were assessed using Analysis of variance (ANOVA), Student's $t$-test, or the Wilcoxon rank-sum test. ANOVA was initially used for multiple comparisons; if significant differences were found, individual $t$-tests or the Wilcoxon rank-sum test were used to distinguish between groups.

\section{Acknowledgements}

This study was supported by grants from the Korea Ministry of Health and Welfare, Republic of Korea A050193, $A 050288$, and $A 080711$, and from the Korea Science and Education Foundation RO1-2007-000-11026-0. 


\section{References}

Antithrombotic Trialists' Collaboration. Collaborative metaanalysis of randomised trials of antiplatelet therapy for prevention of death, myocardial infarction, and stroke in high risk patients. BMJ 2002;324: 71-86

Au BT, Teixeira MM, Collins PD, Williams TJ. Effect of PDE4 inhibitors on zymosan-induced IL-8 release from human neutrophils: synergism with prostanoids and salbutamol. $\mathrm{Br}$ J Pharmacol 1998;123:1260-6

Bateman ED, Hurd SS, Barnes PJ, Bousquet J, Drazen JM, FitzGerald M, Gibson P, Ohta K, O'Byrne P, Pedersen SE, Pizzichini E, Sullivan SD, Wenzel SE, Zar HJ. Global strategy for asthma management and prevention: GINA executive summary. Eur Respir J 2008;31:143-78

Busse WW, Lemanske RF, Jr. Asthma. N Engl J Med 2001;344:350-62

Busse WW, Lemanske RF Jr. Expert Panel Report 3: Moving forward to improve asthma care. J Allergy Clin Immunol 2007;120:1012-4

Celli BR, MacNee W. Standards for the diagnosis and treatment of patients with COPD: a summary of the ATS/ERS position paper. Eur Respir J 2004;23:932-46

Claveau D, Chen SL, O'Keefe S, Zaller DM, Styhler A, Liu S, Huang Z, Nicholson DW and Mancini JA. Preferential inhibition of T helper 1, but not T helper 2, cytokines in vitro by L-826,141 [4-[2-(3,4-Bisdifluromethoxyphenyl)-2-[4(1,1,1,3,3,3-hexafluoro-2-hydroxy propan-2-yl)-phenyl]ethyl]3-methylpyridine-1-oxide], a potent and selective phosphodiesterase 4 inhibitor. J Pharmacol Exp Ther 2004; 310:752-60

Culpitt SV, de Matos C, Russell RE, Donnelly LE, Rogers DF, Barnes PJ. Effect of theophylline on induced sputum inflammatory indices and neutrophil chemotaxis in chronic obstructive pulmonary disease. Am J Respir Crit Care Med 2002;165:1371-6

Cushley MJ, Tattersfield AE, Holgate ST. Adenosine-induced bronchoconstriction in asthma. Antagonism by inhaled theophylline. Am Rev Respir Dis 1984;129:380-4

Dent G, Giembycz MA, Rabe KF, Barnes PJ. Inhibition of eosinophil cyclic nucleotide PDE activity and opsonised zymosan-stimulated respiratory burst by 'type IV'-selective PDE inhibitors. Br J Pharmacol 1991;103:1339-46

Erdmann AA, Gao ZG, Jung U, Foley J, Borenstein T, Jacobson KA, Fowler DH. Activation of Th1 and Tc1 cell adenosine A2A receptors directly inhibits IL-2 secretion in vitro and IL-2-driven expansion in vivo. Blood 2005;105: 4707-14

Gibson PG, Simpson JL, Saltos N. Heterogeneity of airway inflammation in persistent asthma : evidence of neutrophilic inflammation and increased sputum interleukin-8. Chest 2001;119:1329-36

Green RH, Brightling CE, Woltmann G, Parker D, Wardlaw AJ, Pavord ID. Analysis of induced sputum in adults with asthma: identification of subgroup with isolated sputum neutrophilia and poor response to inhaled corticosteroids. Thorax 2002;57:875-9
Hamad AM, Sutcliffe AM, Knox AJ. Aspirin-induced asthma: clinical aspects, pathogenesis and management. Drugs 2004;64:2417-32

Hidi R, Timmermans S, Liu E, Schudt C, Dent G, Holgate ST, Djukanovic R. Phosphodiesterase and cyclic adenosine monophosphate-dependent inhibition of T-lymphocyte chemotaxis. Eur Respir J 2000;15:342-9

Jackson EK, Mi Z, Gillespie DG, Dubey RK. Metabolism of cAMP to adenosine in the renal vasculature. J Pharmacol Exp Ther 1997;283:177-82

Jaffar ZH, Sullivan P, Page C, Costello J. Low-dose theophylline modulates T-lymphocyte activation in allergenchallenged asthmatics. Eur Respir J 1996;9:456-62

Jatakanon A, Uasuf C, Maziak W, Lim S, Chung KF, Barnes PJ. Neutrophilic inflammation in severe persistent asthma. Am J Respir Crit Care Med 1999;160:1532-9

Keatings VM, Collins PD, Scott DM, Barnes PJ. Differences in interleukin-8 and tumor necrosis factor-alpha in induced sputum from patients with chronic obstructive pulmonary disease or asthma. Am J Respir Crit Care Med 1996;153: 530-4

Kidney J, Dominguez M, Taylor PM, Rose M, Chung KF, Barnes PJ. Immunomodulation by theophylline in asthma. Demonstration by withdrawal of therapy. Am J Respir Crit Care Med 1995;151:1907-14

Kim YK, Oh SY, Jeon SG, Park HW, Lee SY, Chun EY, Bang B, Lee HS, Oh MH, Kim YS, Kim JH, Gho YS, Cho SH, Min KU, Kim YY, Zhu Z. Airway exposure levels of lipopolysaccharide determine type 1 versus type 2 experimental asthma. J Immunol 2007;178:5375-82

Kraft M, Torvik JA, Trudeau JB, Wenzel SE, Martin RJ. Theophylline: potential antiinflammatory effects in nocturnal asthma. J Allergy Clin Immunol 1996;97:1242-6

la Sala A, Ferrari D, Corinti S, Cavani A, Di Virgilio F, Girolomoni G. Extracellular ATP induces a distorted maturation of dendritic cells and inhibits their capacity to initiate Th1 responses. J Immunol 2001;166:1611-7

Lewis HD Jr, Davis JW, Archibald DG, Steinke WE, Smitherman TC, Doherty JE 3rd, Schnaper HW, LeWinter MM, Linares E, Pouget JM, Sabharwal SC, Chesler E, DeMots $\mathrm{H}$. Protective effects of aspirin against acute myocardial infarction and death in men with unstable angina. Results of a Veterans Administration Cooperative Study. N Engl J Med 1983;309:396-403

Lugnier C, Schoeffter P, Le Bec A, Strouthou E, Stoclet JC. Selective inhibition of cyclic nucleotide phosphodiesterases of human, bovine and rat aorta. Biochem Pharmacol 1986;35:1743-51

Morwood K, Gillis D, Smith W, Kette F. Aspirin-sensitive asthma. Intern Med J 2005;35:240-6

Nielson CP, Crowley JJ, Morgan ME, Vestal RE. Polymorphonuclear leukocyte inhibition by therapeutic concentrations of theophylline is mediated by cyclic-3',5'-adenosine monophosphate. Am Rev Respir Dis 1988;137:25-30

Park Y, Chang YS, Lee SW, Cho SY, Kim YK, Min KU, Kim YY, Cho SH, Sung YC. The enhanced effect of a hexameric 
deoxyriboguanosine run conjugation to $\mathrm{CpG}$ oligodeoxynucleotides on protection against allergic asthma. J Allergy Clin Immunol 2001;108:570-6

Pauwels R, Van Renterghem D, Van der Straeten M, Johannesson N, Persson CG. The effect of theophylline and enprofylline on allergen-induced bronchoconstriction. J Allergy Clin Immunol 1985;76:583-90

Pauwels RA, Joos GF. Characterization of the adenosine receptors in the airways. Arch Int Pharmacodyn Ther 1995;329:151-60

Rabe KF, Magnussen H, Dent G. Theophylline and selective PDE inhibitors as bronchodilators and smooth muscle relaxants. Eur Respir J 1995;8:637-42

Rainsford KD, Whitehouse MW. Anti-inflammatory/antipyretic salicylic acid esters with low gastric ulcerogenic activity. Agents Actions 1980;10:451-6

Resta R, Hooker SW, Laurent AB, Jamshedur Rahman SM, Franklin M, Knudsen TB, Nadon NL, Thompson LF. Thompson. Insights into thymic purine metabolism and adenosine deaminase deficiency revealed by transgenic mice overexpressing ecto-5-nucleotidase (CD73). J Clin Invest 1997;99:676-83

Roth GJ, Stanford N, Majerus PW. Acetylation of prostaglandin synthase by aspirin. Proc Natl Acad Sci USA 1975;72:3073-6

Scanlon PD, Connett JE, Waller LA, Altose MD, Bailey WC, Buist AS. Smoking cessation and lung function in mild-to-moderate chronic obstructive pulmonary disease. The Lung Health Study. Am J Respir Crit Care Med 2000;161:381-90

Shimokawa T, Smith WL. Prostaglandin endoperoxide synthase. The aspirin acetylation region. J Biol Chem 1992;

\section{$267: 12387-92$}

Stevenson DD. Aspirin and NSAID sensitivity. Immunol Allergy Clin North Am 2004;24:491-505, vii

Sullivan P, Bekir S, Jaffar Z, Page C, Jeffery P, Costello J. Anti-inflammatory effects of low-dose oral theophylline in atopic asthma. Lancet 1994;343:1006-8

Torphy TJ, Barnette MS, Underwood DC, Griswold DE, Christensen SB, Murdoch RD, Nieman RB, Compton CH. Ariflo (SB 207499), a second generation phosphodiesterase 4 inhibitor for the treatment of asthma and COPD: from concept to clinic. Pulm Pharmacol Ther 1999;12:131-5

Vancheri C, Mastruzzo C, Sortino MA, Crimi N. The lung as a privileged site for the beneficial actions of PGE2. Trends Immunol 2004;25:40-6

Ward AJ, McKenniff M, Evans JM, Page CP, Costello JF. Theophylline--an immunomodulatory role in asthma? Am Rev Respir Dis 1993;147:518-23

Warner TD, Mitchell JA. Cyclooxygenase-3 (COX-3): filling in the gaps toward a COX continuum? Proc Natl Acad Sci USA 2002;99:13371-3

Wenzel SE, Szefler SJ, Leung DY, Sloan SI, Rex MD, Martin RJ. Bronchoscopic evaluation of severe asthma. Persistent inflammation associated with high dose glucocorticoids. Am J Respir Crit Care Med 1997;156:737-43

Yasui K, Agematsu K, Shinozaki K, Hokibara S, Nagumo H, Yamada S, Kobayashi N, Komiyama A. Effects of theophylline on human eosinophil functions: comparative study with neutrophil functions. J Leukoc Biol 2000;68: 194-200

Zidek Z. Adenosine - cyclic AMP pathways and cytokine expression. Eur Cytokine Netw 1999;10:319-28 